\title{
Del trato al contrato: agentes, INSTITUCIONES Y NEGOCIOS EN EL MUNDO COLONIAL NEOGRANAdino. Estudio DE CASO $(1763)^{1}$
}

\author{
Jesús Bohórquez Barrera \\ Universidad Industrial de Santander, Colombia \\ chuchobohorquez@hotmail.com
}

\section{Resumen}

En este artículo se estudian las diferencias entre los tratos y los contratos. Se analiza el papel desempeñado por los agentes y sus pautas de comportamiento (sentimientos y pasiones) en relación con las instituciones coloniales. Se estudian tres elementos fundamentales: el porqué se firma un contrato, la configuración de intereses particulares en el interior de ciertas redes y la manera en que se instaura una acción específica: el acto de negociar. En este sentido, se presenta el papel que desempeñaron documentos no legales, como los vales y los cuadernos de cuenta, en lo que se denominó durante el período colonial el ajuste de cuentas.

Palabras clave: contratos, Nuevo Reino de Granada, Girón, historia económica, siglo XVIII.

\section{Abstract}

This article studies the differences between deals and contracts and analyzes the role of agents and their norms of behavior (emotions and passions) regarding colonial institutions. Three fundamental elements are examined: the reason why a contract is signed, the configuration of particular interests within certain networks, and the way of initiating a specific action: the negotiation. This way, the article studies the role of non legal documents — like vouchers or account books, among others — in the so called settling of accounts during the colonial period.

Key words: contracts, Nuevo Reino de Granada, Girón, economic history, 18th century.

1 Una primera versión de este texto fue escrito en el trabajo Espacios, cosas y sentimientos. Vida rural en el Nuevo Reino de Granada: una historia económico-cultural de las cuencas del Sogamoso y el Lebrija. Con algunas correcciones el texto fue presentado en el IV Simposio de Estudios sobre América Colonial (CASO), Universidad de Minas Gerais, Belo Horizonte, Brasil, en noviembre de 2008. Agradezco la lectura y comentarios de Julian Andréi Velasco. 
... para que los menores respeten a los mayores [... ] y las partes hablen con la modestia que deban en sus escritos sin desacatar a los señores jueces y superiores.

Doctor don Juan Tomás de Arango, abogado.

\section{- Primero: la escritura de la escritura y las cláusulas contractuales}

El 10 de enero de 1761 se firmó en la ciudad de Girón una escritura pública en la que don Joseph Antonio de Navas se obligó como principal deudor, junto con su hermano don Egidio de Navas como principal pagador. La suma de 400 pesos fue reconocida al Convento de Santa Clara de Pamplona "en moneda usual y corriente $[\ldots]$ según y como los reconocía don Fernando Martín Nieto”. La comunidad de religiosas tenía como su representante legal en la ciudad de Girón al hermano de los deudores, don Ignacio de Navas, quien también firmó la escritura. Para respaldar la "suma" se cargó una estancia de potrero en el sitio de Salazar, con 60 cabezas de ganado vacuno, ocho mulas, un negro de 16 años y una mulata con su hijo pequeño (“Causa”, ff. 170v.-173v.).

Varias operaciones ${ }^{2}$ pueden realizarse con este tipo documental. Por ejemplo, se podría encadenar en una serie, en un entramado de cifras prestas a explicar los movimientos de los estados crediticios de la época. Otra opción consistiría en contar uno a uno sus componentes, desde el aparato legal hasta la misma forma: un censatario que recibía el dinero y quedaba en la obligación de pagar los réditos anuales al censualista, y uno o varios fiadores (según la cantidad solicitada), quienes debían poseer reconocida solvencia (material y simbólica) para responder en caso de que el deudor no pudiera pagar los réditos o la deuda ${ }^{3}$. En cualquiera de las elecciones, es decir, tanto

2 Sobre el problema de las operaciones, véase De Certeau.

3 Véase, por ejemplo, Colmenares (Cali 61-77), Ferreira y Soulodre-La France (91-112). Se debe decir que en buena parte de los casos la Real Justicia entregaba los bienes a uno de los fiadores y este se hacía cargo de la suma reconocida. Por eso de los fiadores no se desprenden únicamente las redes personales del principal pagador, sino además sus propios juegos y apuestas. 
en la incorporación de una cantidad en una serie numérica o en la descripción del contrato, se da por descontando que la suma enunciada (en este ejemplo los 400 pesos) pasó de las manos del censualista a las del censatario ¿Por qué? Porque la escritura del contrato determina cómo sucedieron los hechos ${ }^{4}$.

Sin embargo, existe otra operación que se podría realizar con este mismo documento, para descubrir otros fenómenos que se relacionan tanto con la disponibilidad de dinero como con el papel desempeñado por los roles jurídicos. Así, se podría preguntar ¿por qué se firma el contrato?, y a partir de ahí intentar responder por las condiciones que dieron lugar a la firma de dicho documento. En otras palabras, se busca examinar de manera minuciosa la documentación para mostrar las diferentes variables que intervienen en su configuración.

Este análisis documental quiere abordar un problema específico que espera ser debatido en la historiografía colonial: el papel de los agentes y sus comportamientos ${ }^{5}$ en su interacción con las instituciones. Por ello este artículo tiene como objetivo identificar el papel que desempeñaban ciertas pautas de comportamiento y la manera como intervenían en un tipo determinado de acción, a la que se le puede nombrar como el acto de negociar. De lo que se trata es de plantearle una tercera pregunta al mismo documento: ¿cómo se efectuaba el acto de negociar, que se establecía gracias a las relaciones mantenidas entre los sujetos? Y en relación con ello, ¿las cantidades expresadas en los contratos representan dinero en circulación o, más bien, aluden a "sumas reconocidas" (lenguaje utilizado en la época) ${ }^{6}$ ?

$4 \quad$ Si se arman series estadísticas, se da por hecho que el dinero circuló y, por lo tanto, la totalidad repartida en períodos precisos representa las cantidades que hacían parte de las partidas crediticias de las cuales disponían los sujetos del período colonial; pero si no se suman partidas, sino que se realiza una descripción de los datos de la escritura, se termina por otorgarles a los agentes ciertos papeles que sólo aparecen en el mundo jurídico, o sea, en la enunciación que se debe abrir con la aceptación del contrato: este reconoció tal cantidad, las instituciones religiosas eran las únicas fuentes crediticias de la época, etc.

5 Sobre el papel de las emociones, véase Elías.

6 Para el debate sobre la circulación de moneda en las colonias americanas, véase Assadourian, Romano e Ibarra. 
Las respuestas a estas preguntas aparecen al analizar las operaciones o tratos que permitieron establecer un contrato específico. El ejemplo de los hermanos Navas, de la ciudad de Girón mencionado al principio, podría ayudar a responder las preguntas ${ }^{7}$. Como se verá, la única manera de comprender las maneras en que se llevaban a cabo ciertas negociaciones es preguntándose por lo que tuvo lugar antes de la firma del contrato y después de esta. Si bien el punto de partida está constituido por los enunciados de una clase específica de texto (el notarial), el problema remite al juego establecido entre las acciones que fueron puestas en otra clase de enunciados, materializados en un género textual diferente: los procesos civiles.

Es importante señalar la poca atención que la historiografía colonial ha dado a este tipo de documentos. Buena parte de las investigaciones han concentrado su atención en los juicios de tipo criminal o de acusaciones que atentan contra las leyes religiosas o civiles ${ }^{8}$. Los documentos de tipo civil se han tomado como fuentes de donde se obtiene información que, en muchos casos, se recolecta, pero se desliga de las particularidades a las que pertenece. Falta, sin duda, realizar trabajos donde se detalle cómo eran instauradas y llevadas las demandas por pesos, por créditos, por telas o por incumplimiento de contratos.

El trabajo está dividido en tres partes. En la primera se muestra la manera como la firma del contrato lleva a la instauración de una demanda específica y se analizan ciertos elementos que resultaban fundamentales al momento de realizar los contratos: las relaciones entre hermanos y las pautas de negociación. Así, mientras la primera parte se ocupa de responder

7 Si bien para este artículo se acude al análisis de un solo caso, se debe decir que su estudio tiene como respaldo documental la lectura de la base total de demandas civiles ejecutadas en la ciudad de Girón entre 1704 y 1776, de las cuales se eligió este caso representativo. Además, se basa en la revisión pormenorizada de los protocolos notariales firmados en la misma ciudad durante el mismo período. De los libros de escribanos se recolectaron aproximadamente 1.500 transacciones entre censos, operaciones por tierra, compra y venta de esclavos, hipotecas y aceptación de deudas.

8 Véase, por ejemplo, Ceballos. 
por lo que pasó antes de la firma de la escritura, en la segunda se exponen ciertas pautas de comportamiento que se reconocen como adecuadas e inadecuadas al momento de cobrar; se trata de pasiones y virtudes que resultaban de especial relevancia para mantener o destruir ciertas redes personales. Por último, se analiza el problema del ajuste de cuentas. Se quiere mostrar con ello cómo, en un trato específico, se alcanzaba la satisfacción entre las diferentes partes.

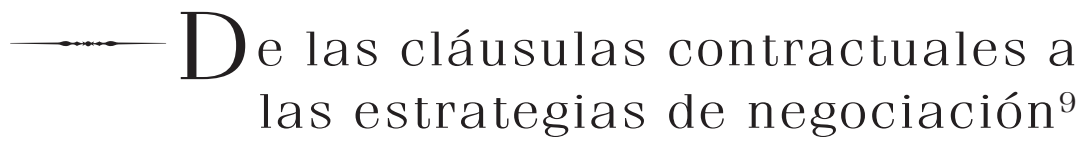

Cuadro1. Principales actores

* Joseph Antonio de Navas: censatario-demandado.

* Egidio de Navas: fiador-demandado.

* Ignacio de Navas: apoderado del Convento de Santa Clara-denunciantehermano mayor.

* Fernando Martín Nieto: alguacil mayor, comerciante y antiguo censuario.

* Joseph de Amate: comerciante de Mompox y acreedor de don Egidio de Navas.

* Don Diego Mantilla: yerno de don Ignacio de Navas.

El apoderado del convento se presentó tres años después de la firma de la escritura ante la Real Justicia para cobrar los 400 pesos y los dos años de "réditos" del censo, pues a pesar de haber "practicado las más atentas expresiones", no había podido conseguirlo. Solicitaba se notificara a los deudores la satisfacción "puntual", así como el pago de otros 160 pesos que le eran deudores. Para instaurar su demanda presentó un recibo firmado por él mismo, en que se había escrito: 
En 17 de julio del año pasado de 763 Recibí de mano de don Diego Mantilla de don Joseph Antonio de Nava veinte pesos rédito de cuatrocientos que reconoce a favor del convento de Santa Clara de la ciudad de Pamplona de un año cumplido a nueve de noviembre del año pasado de 1761 y para que conste firmo el presente. San Juan Girón a 7 de marzo de 1764 Ignacio de Navas. (“Causa”, f. 174r.)

Según la declaración del deudor principa ${ }^{10}$ (ahora atrapado bajo el rol de demandado), por "mano" de don Egidio había dado 40 pesos en cuenta de los réditos que se le cobraban, pues este le tenía 50 pesos del dinero que su otro hermano le había dejado cuando murió ${ }^{11}$; dinero que "ni antes ni después me ha entregado" " "de cuya cantidad podía haber abonado los réditos" (“Causa”, f. 177r.). El problema no era la no entrega del dinero, sino la confusión respecto a quien se debían abonar las partidas que don Egidio entregó al apoderado del convento por medio de su yerno don Diego Mantilla.

Al yerno de don Ignacio se le entregaron 86 pesos "sin otra razón”, y a pesar de que don Joseph se había presentado en casa del apoderado del convento ${ }^{12}$ solamente le "encargó dijese a su hermano don Egidio viniese a darle razón a que cuentas se acumulaban estos pesos" si a los muchos que le debía don Ignacio o a los réditos que "tenían caídos". A pesar de que en su testimonio don Joseph Navas negó esto, resulta curioso preguntarse por la manera como se ordenaban las cuentas: por una parte, don Joseph no ve como indebido que su hermano tomara cierta cantidad para pagar sus deudas y, por la otra, la poca claridad que presenta en el momento de arreglar las partidas, pues no se sabía en qué forma se debían distribuir los abonos. Al parecer don Egidio no concurrió ${ }^{13}$ a la casa de su hermano "por cuya razón" este arregló las cuentas, dividiendo los 80 pesos, de la siguiente manera:

Ahora con el rol de demandado, pero también ejercía el rol de hermano menor.

11 Según el testimonio de don Joseph, era menor de edad en el momento de la muerte de don Bartolomé de Navas. Por dicho motivo don Egidio de Navas se hizo cargo de esos 50 pesos, así como de otras cantidades correspondientes por la división de sus bienes.

12 Ahora bajo el rol de denunciante, pero todavía con el rol de hermano mayor. Este juego de roles resulta fundamental para comprender el proceso.

13 "Lo que no se pudo conseguir". 
* 60 pesos para don Egidio de tres años de réditos causados por los 400 pesos reconocidos al favor del convento.

* 20 pesos para don Joseph de los que debía "satisfacer como consta del cuaderno".

Ante las declaraciones y los arreglos de don Ignacio, el denunciado exigió que se hiciera comparecer a don Egidio para que bajo juramento de la religión, "en la presencia de mi hermano mayor", testificara si le había entregado 80 pesos a don Diego Mantilla "y le dijo que los cuarenta eran míos", "y si después de algunos días se lo dijo a nuestro hermano mayor". El apoderado del convento no estuvo de acuerdo con esta petición y en su respuesta al escrito respondió dejando clara la posición en la que se encontraba respecto de sus dos hermanos:

... que insistiendo el referido en la no satisfacción de lo que tan justamente es deudor quiere o pretende para más confundir esta instancia y alucinar la mente de Vuestra Excelencia que don Egidio de Navas haga cierta declaración [ ...] y que a su juramento sea yo presente y como quiera que esta a mí ni a mi parte sea favorable por el odio y la mala voluntad que me tiene por razón de cobrarle mis intereses y los que a mi parte corresponden la tacho. (“Causa”, f. 180r.)

El problema que atravesaba el pleito no era simplemente el del cobro de los 40 pesos de réditos. En el modo de ver de don Ignacio, su hermano don Egidio le tenia odio y mala voluntad por el hecho de tenerle interpuesta otra demanda para cobrarle ciertas partidas de las que le era deudor $y$, sobre todo, por proceder al embargo de sus bienes; embargo que llegaba al punto de ponerlo "en consternación de dejarlo en la calle". Además, el problema no se limitaba simplemente a esto. Si bien en una primera declaración se afirmó haber pagado los intereses, después el pleito dejó al descubierto otros parámetros de negociación. Es esto precisamente lo que interesa destacar. A pesar de los argumentos de don Ignacio, la declaración fue tomada. Don Egidio afirmó que en el mes de junio de 1763 "requirió" a su hermano sobre los réditos que debía:

... que no le expuso que cantidad era y que después de San Pedro del citado año le trajo ochenta y seis pesos pero que no habiéndole encontrado se los entregó a don Diego Mantilla para que a su citado hermano se los diera y le 
dijera que esos eran los réditos de uno y otro que cuando volvieran al lugar le daría el recibo y que a pocos días vino y se lo dijo vocalmente expresándole que cuarenta pesos eran de don Joseph Antonio y los cuarenta y seis del declarante y le preguntó cuánto más debían para pagar dándole la minuta [de] la escritura para ver lo que debía don Fernando Nieto. (“Causa”, f. 180v.)

Además de la declaración tomada a don Egidio, el demandado exigió que se mandara al escribano y diera un testimonio donde este certificara si era cierto que había estado presente cuando don Egidio "requirió" al alguacil mayor don Fernando Martín Nieto para cobrarle 9 pesos y 4 reales de réditos de los 400 pesos que había reconocido don Joseph. Según el escribano, don Fernando contestó que "a quien se los debía era a su compañero don Ignacio supuesto a que la entrega de los doscientos que me debía dar no fue al tiempo en que yo me obligué” (“Causa”, f. 181r.).

¿Cuál es el papel de don Fernando Martín Nieto en el conflicto? Con el testimonio del escribano quedó claro que don Egidio de Navas "requirió" a don Fernando para cobrarle la cantidad correspondiente a los réditos de 200 pesos que le debía en vista de que el censo había recaído a su nombre ${ }^{14}$. Al parecer de don Fernando, a quien le debía el dinero era a don Ignacio ${ }^{15}$ y no a las personas que habían tomado el censo. Según aparecía en el protocolo notarial, el dinero recibido por don Joseph Navas era "en moneda usual y corriente", "según y como los reconocía don Fernando Martín”. Es decir, en términos de contrato, el dinero debió ser entregado al representante de las monjas de Pamplona para que este lo entregara al nuevo censuario. Ni una cosa ni la otra. A pesar de que en la escritura aparece una cantidad de 400 pesos, parece que al menos 200 de esos no corrieron en moneda, como se expone en la escritura. Este hecho resulta interesante, pues permite establecer un primer lugar de emergencia del objeto de este discurso: el de la negociación. Don Joseph Antonio de Navas explicó por qué don Fernando era deudor de esos réditos:

14 Es importante señalar que en el testimonio del escribano aparece don Egidio y no don Joseph como la persona que tomó el censo a su cargo.

15 Por ser este el apoderado del convento. 
... pues aunque por mi escritura consta que recibí cuatrocientos pesos de las madres monjas de manos de su apoderado no fue pues sólo fueron doscientos los que me entregó y los otros quedó de dárselos el indicado alguacil mayor y no los entregó hasta once meses después como consta de recibo que solemnemente presento por lo que debía estos réditos como lo comprueba la certificación del escribano pues si contempla que eran de mi cargo el enunciado don Fernando me los hubiera dado. (“Causa”, f. 181)

El recibo con el cual se buscaba sustentar este hecho permite comprobar que las partidas no circularon. Se trata de un recibo firmado por don Joseph Amate, en la ciudad de Mompox, con fecha de 2 de octubre de 1761: "Recibí de Joaquín Delgado doscientos patacones que por mano de don Fernando Martín Nieto me remitió don Egidio de Navas por cuenta de mayor cantidad que me es deudor y para que conste firmo el presente" ("Causa, f. 181). Los 200 pesos hacían parte de un arreglo, al parecer entre comerciantes. Se deben señalar varios elementos respecto a las negociaciones realizadas:

a. Es imposible tomar el contrato como apoyo del reporte de los hechos, pues como se ha señalado a lo largo del texto, existen condiciones que permitieron el surgimiento de ciertos enunciados en su interior. Por ello se debe destacar el arreglo que llevó a don Egidio a aceptar la renuncia de los 200 patacones a la espera de que fueran entregados a uno de sus acreedores en la ciudad de Mompox, el cual, seguramente, también tenía negocios con don Fernando Martín Nieto. A pesar del arreglo, este tardó 11 meses en entregar el dinero o en arreglar con el proveedor. Así, el recibo remite a otro problema: el del ajuste o arreglo de cuentas; es decir, ya no al antes sino al después. Respecto a esto se deben señalar dos elementos: los contratos aparecen en relación con una situación y prácticas específicas (ciertos negocios entablados bajo ciertas redes) y en algunas ocasiones envían a un arreglo posterior que se materializa en la escritura de una nueva cuenta. Ella debe hacerse debido a la consolidación de la red establecida en la primera negociación o a su desajuste (redes de desequilibrio). El ejemplo de los Navas es claro sobre esta última opción.

b. Las negociaciones entre los hermanos: bien queda claro que la denuncia se instaura contra don Joseph, pero en los testimonios se reconoce 
que el dinero terminó supliendo una deuda de su hermano ${ }^{16}$. No obstante este hecho, al lo largo de todo el proceso don Joseph continuó defendiéndose en "primera persona" e incluso atacando a su hermano mayor a nombre propio, lo cual parece sorprendente, pues ¿por qué continuar el proceso si él no era el deudor? Aquello tan explícito en el contrato termina por tener otra condición de emergencia: tiene sentido que don Joseph aparezca como censatario en tanto se esconde el hecho de que el deudor era don Ignacio. Más que firma de un contrato, más que censo tomado de una institución religiosa, el texto notarial remite a estas pequeñas negociaciones entre hermanos. El caso es bastante interesante, puesto que se enmarca en una partida jugada entre tres jugadores, donde dos de ellos terminan siendo acusados por el que tenía las relaciones directas con la institución. Algún inconveniente debió de haber surgido para que los tres entraran en conflicto, y más, para que llegaran al extremo de catalogar sus relaciones como de enemistad y odio. A continuación se analizan estas relaciones y de la forma como empezaron a ser parte de un juego de pasiones.

\section{Las pasiones y las pautas de comportamiento: elementos indispensables para establecer y mantener una red de negociaciones}

A lo largo de la primera parte de este texto aparece la familia como un soporte fundamental de esas negociaciones en las cuales emergían los enunciados contractuales. Sin embargo, también se nota como esta no puede ser considerada un bloque que se conservaba a lo largo de la vida de los agentes; todo lo contrario, las alianzas sólo lograban sostenerse mediante

16 Lo que también queda en claro con el testimonio de don Ignacio y la declaración jurada de bienes de don Egidio "es declaración que el día de san Pedro de este próximo año pasado le entregué a mi hermano don Ignacio de Navas ochenta Patacones por mano de su yerno don Diego Mantilla y fuera por razón de los réditos de los cuatrocientos pesos que reconozco yo al convento de santa Clara y otra tanta cantidad que reconoce el dicho hermano y no ha dado recibo" (“Civil”, ff. 332r.-333r.). 
un "incesante trabajo de mantenimiento" (Bourdieu, El sentido 275 y Esquisse). Ahora bien, para estudiar este hecho se puede seguir en el análisis del ejemplo de los Navas considerando sus testimonios sin caer en la narración propuesta por el proceso judicial, a fin de intentar aproximarnos a algunos conceptos que identifiquen las maneras y pautas de comportamiento, es decir, la red de relaciones en las cuales estaban imbricadas las acciones de los sujetos: las emociones, los valores y las pasiones que también servían de sustento a las negociaciones.

En vista del supuesto arreglo que don Ignacio había realizado con los 86 pesos entregados, y al dejar en claro que alguna parte de la deuda cobrada correspondía al antiguo censuario, don Joseph entró en conflicto directo con su hermano mayor. En sus testimonios advirtió algunas maneras como este se había comportado frente a ellos. Así, de su memoria tomó varios ejemplos que terminaron por agravar las relaciones, ya de por sí bastante tensas entre los hermanos. En una de ellas se refirió a la forma como le fueron cobrados los réditos:

... se ve recibió ochenta y seis pesos por mano de su yerno don Diego y que este no le dio razón ninguna lo dudo tanto que a según no es así pues es tanta verdad como lo que asienta en su demanda de haber practicado la más atentas expresiones para persecución de mis réditos siendo siniestro pues sólo una vez estuvo en mi casa estando yo en cama con grave calentura y válido de ella fueron tales sus demasías y desacatos que a no haber estado yo tan postrado como estaba a palos le hubiera acordado las obligaciones con que nació y lo educó nuestro padre. (“Causa”, f. 183r.)

Existen maneras de cobrar, pautas que deben tener como soporte "atentas expresiones". Esto respecto a los negocios y a las pautas entre familiares. Como sostiene don Joseph, en el lado contrario aparecen las demasías relacionadas con los desacatos. En ocasiones se llegaba al extremo de cobrar bajo pautas que no estaban acordes con las indicadas por las restricciones sociales impuestas a los individuos. En el mismo testimonio se recalcó que don Ignacio no sólo tenía "poco fundamento" para inquietar a la justicia, sino para tener a don Joseph preso en la ciudad y comportarse con su hermano don Egidio del modo en que lo estaba haciendo. Se debía 
tener en cuenta las acciones tomadas por el denunciante, al tratar de tachar el testimonio de don Egidio. Esto no le "espantaba" a don Joseph, pues tenía a su hermano "puesto en consternación de dejarlo en la calle", en razón de la demanda que le había efectuado por:

... cortos pesos que si con buen modo se los hubiera cobrado y no con la soberbia que acostumbra se los hubiera pagado y con la demanda los pierde cuya acción señor de tachar a su hermano como testigo en juicios le suplico a su merced le gradué por la de Caín pues si aquel quita la vida a su hermano yo como ignorante no sé que motivo tuvo por mi hermano mayor para tachar a nuestro hermano en juicio fue por veinte pesos con que se ve señor $[\ldots]$ quien por veinte pesos reputa a un hermano por infiel testigo? Que concepto se puede hacer de él. ("Causa”, ff. 183r.-184v.)

Las declaraciones de don Joseph dejan ver ciertas pautas de comportamiento que se veían como indebidas en la sociedad colonial. El actuar con demasías y desacatos era una consecuencia de que los sujetos olvidaran las "obligaciones" con que habían nacido o con las que habían sido educados. Además, se hacía referencia a cierta emoción no controlada: la soberbia. Una forma de actuar por demás condenada en la Biblia. Todo esto está relacionado con la manera cómo surge, es decir, como se puede hacer, un concepto de alguien.

Estos patrones se suman a otros enunciados en los testimonios de don Ignacio en contra de su hermano menor. A pesar de no querer contestar las "dicteriosas e ineducables razones" las refutó, pues estaban "sugeridas por el luciferino director que le contribuye falsas e indignas palabras para vengar su odio y mala voluntad injuriándome y atribuyéndome lo que acostumbradamente usa para divertir caudales ajenos" (“Causa”, f. 184v.). De este modo, si don Ignacio había sido catalogado de soberbio, don Joseph era visto como una persona con la capacidad de vengar una pasión como el odio; además, por tener mala voluntad hacia uno de sus hermanos. Su venganza se veía representada en su manera de agraviarlo atribuyéndole cierta costumbre: la diversión de caudales ajenos. ¿A qué hace referencia? Al parecer dicha pauta de comportamiento era muy usada en las negociaciones: la palabra divertĕre remite al hecho de desviarse, apartarse del camino, de recurrir a, de llevar por varios lados (Sopena 516). Lo que se ponía en duda era su buena reputación. 
Pero no bastándole con referirse a sus supuestas maneras de comportarse, don Ignacio alegó a su favor el hecho de que don Joseph viviera en la casa de su hermano como "a pupilo" y resaltó también la manera indebida en la utilización del lenguaje y lo requirió a usar "los términos correspondientes en sus escritos para alegar en tribunales tan respetuosos como el de Vuestra Excelencia y trato con personas de las circunstancias que la mía goza” (“Causa”, f. 185r) ${ }^{17}$. En la asesoría del abogado don Tomás Arango se pone en claro una de las razones del conflicto. En este caso el doctor o, para hablar con la precisión debida, la objetividad puesta en su decreto, favoreció a don Ignacio. La balanza de la justicia se debía inclinar hacia uno de los lados, pero no se puede olvidar que sólo un cuerpo en una situación precisa está en capacidad de percibir el arriba y el abajo, la inclinación izquierda y derecha, en total, el lado hacia el cual se inclinará la balanza:

... y siendo la persona de don Ignacio de Navas respetable por sus canas y circunstancias haber obtenido el empleo de alcalde ordinario en esta ciudad por tres ocasiones e igualmente los demás empleos honorificos de esta república con el acierto que es notorio y ser hermano mayor del predicho don Joseph Antonio quien apenas manifiesta barba siendo permitido en derecho la corrección y castigo de los hermanos mayores a los menores me parece injurio y agravio el citado don Joseph Antonio al referido don Ignacio su hermano con las palabras que [de] no haber estado tan postrado como estaba a palos le hubiera acordado las obligaciones con que nació y lo educó nuestro padre palabras que tienen sabor de parricidio e igualmente se cometió en proferirlas en juzgado tan serio como el de Vuestra Excelencia $[\ldots]$ y para que los menores respeten a los mayores especialmente her-

17 Después del oficio presentado por don Ignacio aparece la primera asesoría del abogado don Juan Tomás de Arango, quien decidió entre otras cosas que (a) si bien en "regla general" era admisible la testificación del hermano por el hermano, no tenía lugar cuando los hermanos tenían bienes comunes y vivían en el mismo domicilio "con que viviendo don Joseph Antonio de Navas no sólo en el domicilio sino en la misma casa de don Egidio y además de tenerlo [don Ignacio] igualmente demandado en juicio soy de sentir se debe declarar no hacerse fe la testificación" (don Ignacio conocía el manejo de la ley, por eso había sacado a relucir en sus declaraciones que "con quien a vivido como a pupilo"; conocer la ley es llevar la realidad, envolviendo en la retórica de un lenguaje hacia el rincón donde todas las cosas pueden ser posibles o nada puede tener lugar); (b) que don Joseph pagara los réditos debidos e hiciera nuevo seguro con fiadores que gozaran de bienes suficientes; (c) no se podía admitir la mutua compensación que pretendía con la herencia de su hermano Bartolomé, sino que en caso necesario debería entablar la debida demanda contra su hermano don Egidio para el cobro de ese dinero, y (d) entablar demanda contra don Fernando Martín Nieto por los 9 pesos y 4 reales que le debía. 
manos y las partes hablen con la modestia que deban en sus escritos sin desacatar a los señores jueces y superiores. (“Causa”, f. 186)

La respuesta de don Joseph ante el decreto del abogado no se hizo esperar. No sólo se ocupó de contradecir el dictamen, sino que retóricamente impuso otros argumentos basándose en leyes y en interpretaciones tomadas de ciertos abogados. Se debe tener en cuenta que en este caso el cruce de fuerzas se dio entre tres vecinos importantes de la ciudad ${ }^{18}$, personajes que sabían leer y escribir, que ocupaban su tiempo leyendo ciertos textos, la recopilación de leyes, vidas de santos, textos de gramática. Por esto se cuenta con la ventaja de que tenían el dinero para hacer de sus escritos amplios memoriales de dos y hasta tres hojas: se respondía de manera amplia, esbozando ejemplos, caracterizando personalidades, adjetivando la realidad, proponiendo argumentos sacados de la circularidad de un lenguaje, de la situación de un cuerpo.

La cantidad de lo que se podía dejar por escrito marcaba el lugar que alguien ocupaba. No era lo mismo no encontrar quien hiciera un "escrito" a pagar por dejar en la objetivación del tiempo una hoja tras otra: esa era otra manera de reconocer la posición que cualquiera ocupaba dentro del conjunto. Los argumentos de don Joseph son bastante llamativos. Definitivamente no estaba de acuerdo en pagar el dinero exigido por don Ignacio y para refutarlo utilizó una figura retórica el exemplum:

Dos mujeres concurrieron en aquel juicio primero de Salomón demandando cada una el hijo que representaron tener igual derecho y la justa y sabia determinación de aquel rey fue que se dividiera el infante: espero de la justificación de Vuestra Excelencia que conformándose con sentencia de tanta autoridad seguida de todos los doctores sin discrepar alguno declare que la cantidad de los ochenta pesos es partible entre mi hermano don Egidio y yo desaprobando la división que fijo mi hermano don Ignacio sin facultad jurisdicción ni consentimiento nuestro. ("Causa”, f. 188r) ${ }^{19}$

18 Al respecto, véase Guerrero.

19 La respuesta de don Ignacio no resulta menos interesante "formar concepto de la sentencia de Salomón tan inconexa y desemejante de la presente, pues aquella fue preferida para conocer por los efectos naturales de los litigantes a quien pertenecía el infante y no con ánimo de que se cumpliera la sentencia, pues a Salomón de ningún modo le era lícito hacer quitar la vida al infante sino es que se diga que tenía mandato de dios para hacerlo y es evidente que que (sic) si de aquella máxima sabia 


\section{Entre los factores del conflicto no estaba simplemente la manera en que} don Ignacio había repartido los 86 patacones, sino el hecho de que se hubiera tomado la facultad de hacerlo. ¿Con qué autoridad se creía el hermano mayor para tomar sus decisiones? Era precisamente un sentimiento el que mantenía a don Joseph en el proceso, a pesar de saber que el dinero por el cual era demandado no había entrado en su poder. Se enfrentaba por la independencia, por el deseo de reconocimiento, de no ser menos y por no permitir que otros manejaran sus caudales o tomaran decisiones por su cuenta (Daumas).

no hubiera resultado el conocimiento a quien pertenecía el infante no se hubiera verificado su división sino que como cosa individua sin estimación de precio para la igualdad en el derecho dudoso lo hubiera adjudicado a quien hubiera querido o se lo hubiera quitado a ambas partes con que no resultando en nuestro caso dudoso ninguna en la pertenencia del dinero por ser privadamente obligado don Egidio de Navas a unos y otros réditos ser quien es" (Causa ejecutiva, $\mathrm{f}$. 194r.). ¿Qué interesa subrayar de estas declaraciones? Primero, si bien se utilizan casos extraídos de la Biblia, resulta más significativo la manera como son interpretados de manera diferente por cada uno de los agentes. La interpretación dada a cada lado era diferente y estaba sujeta a la situación en la que se encontraba cada persona. El ejemplo, uno sólo, tomaba significados opuestos. Se debe señalar esto porque se tiende a pensar que las disquisiciones teológicas eran las únicas fuentes de donde los sujetos bebían conocimiento. No se trata de negar eso sino de ilustrar cómo las cosas tomaban su sentido dependiendo de la situación donde se encontraba quien trataba de trasmitirlas, de ponerlas en práctica (como en una conversación).

El argumento se estira, se recubre, termina por ocultarse tras los intereses puestos en juego. Se sobrecarga dándole otro sentido. El ejemplo, aquello utilizado para llamar la atención o con que llamar la atención, puede tomar los más diversos significados. Pensar en la pura y recta teología es conveniente sólo hasta cierto punto, únicamente con la condición de ponerla a rodar entre las pasiones y sensaciones de los individuos que siempre lo untan todo, le atribuyen otros efectos para crear efectos; no se trata de corrupción, más que de eso y de apropiación, de las infinitas posibilidades para resolverse en la práctica. Lo que se quiere presentar con este ejemplo es precisamente que si bien existían ciertos parámetros de "religiosidad" interiorizada, esta se hallaba sujeta, controlada, interiorizadamente exteriorizada en tanto permitiera entablar contacto. Queda por pensar en la posibilidad de repensar la manera como los discursos dispuestos en los espacios puestos para dar un orden (p. ej., las iglesias) eran usados por los sujetos, de cómo la circularidad (sobre este concepto ver Ginzburg) del conocimiento permitía crear otras formas de conocimiento, tal vez no tan teóricas como prácticas, liberadas de sus significados y recargadas, adjetivadamente objetivadas sin disponer de la manera como se había objetivado con anterioridad, o tal vez sí. En segundo lugar se debe tener en cuenta que el argumento es utilizado para poner la justicia en cierta dirección. Lo terreno se debe combatir con lo celestial, y ante cualquier señal de injusticia son precisamente estos los argumentos que deben ser utilizados, pues la justicia terrena no puede oponerse a la celestial, ejemplo a seguir. $\mathrm{Al}$ respecto véase Duby (Los tres órdenes). 
A pesar de que apenas "manifestaba barba", deseaba imponer su punto y para eso tenía el respaldo de su otro hermano, quien se encontraba envuelto en una grave dificultad. Así, parece que los conflictos familiares no surgían únicamente entre parientes lejanos o entre aquellos con quienes se entablaban alianzas. Dentro de los núcleos aparecían ciertos conflictos relacionados con problemas generacionales. Era difícil mantener el orden intergeneracional a no ser que aparecieran objetivos comunes. Se trataba no sólo de problemas entre primos o parientes lejanos, sino de la manera como se estructuraban las relaciones entre los hermanos. Don Joseph tenía vínculos más fuertes con don Egidio que con don Ignacio, y en sus declaraciones deja en claro que ambos jugaban en conjunto.

Las relaciones entre los dos eran tanto más estrechas por tener fijada la residencia en la misma casa ${ }^{20}$. Con esto se pueden resaltar dos tipos de alianzas: las dadas por relaciones de parentesco y las establecidas como lazos de amistad ${ }^{21}$. Un patrón característico de las pautas de comportamiento del período colonial era el reconocimiento de los límites entre la una y la otra: una cosa son las relaciones por alianza/amistad, y otras, aquellas relaciones por consanguinidad. El hermano menor había escogido mantener relaciones más estrechas con uno de sus hermanos, mientras el otro los miraba no como parientes, ni aliados, sino como enemigos:

... es público constante y notorio señor Gobernador con notoriedad de hecho y derecho que se ha declarado por enemigo de sus hermanos nuestro hermano don Ignacio y se justifica en el mismo hecho de haberme demandado ante vuestra excelencia tenerme preso la ciudad por cárcel y pedir en juicio con tanto ardor contra mi y los otros hermanos por dinero ajeno y como apoderado general con grave perjuicio no sólo de nuestros intereses sino de nuestro honor acciones reprobadas no sólo en lo república cristiana sino en la de la humana política y esto se manifiesta en lo público como se portara en lo privado no se yo que por hermano mayor estamos obligados a tolerar semejantes ajamientos bien que así lo dicta la prudencia pero siendo virtud más propia de los mayores y de los hombres de

20 Sobre el significado de la organización del espacio familiar en Europa occidental, véase Sarti, Le Roy Ladurie, Braudel y Duby (Economía rural).

21 Pierre Bourdieu ha llamado la atención sobre las diferencias entre reglas y estrategias de parentesco. Véanse sus trabajos: "De la règle aux stratégie" y Le bal des célibataires (167-205). 
canas faltando en ellos no es de admirar que carezca de esta joya un hombre que apenas manifiesta barbas. (“Causa”, f. 188v.) (cursivas mías)

Era reprochable la manera como su hermano privilegiaba el cobro del dinero ajeno sin considerar a sus hermanos (a si se tratara del dinero de una institución religiosa: entiéndase dinero sacro); pero se podía soportar menos el hecho de que por su proceder ocasionara grave perjuicio a sus intereses y a su honor. Sin lugar a dudas, estos dos hechos eran reprobados, pautas de comportamiento rechazadas con las cuales se restringían ciertas maneras de actuar. Además, sobresale la manera como se organiza el mundo del cual se hace parte. Para don Joseph aparecen por lo menos varias divisiones donde las reglas que coaccionan las interacciones con los otros pueden o no coincidir del todo: una cosa es el orden establecido en la república cristiana, y otra, la de la "humana política". Sin embargo, existían otras dos esferas: el mundo de lo público y el de lo privado. A este respecto quedan elementos por investigar: ¿cuáles son las pautas por seguir en cada una de las instancias del orden colonial? Es de resaltar, sobre todo, la manera como don Joseph establece la clara división entre las cuatro. En el orden de lo público aparece el mantenimiento de cierta imagen, la fama que se debía tener, en otras palabras, el mantenimiento del honor ${ }^{22}$. Pero ¿qué sucedía en lo privado?

Al parecer las relaciones entabladas durante este período correspondían en su totalidad a la vida pública, es decir, las líneas de división entre lo público y lo privado prácticamente no existían. Todo parecía ser de carácter público. Por eso todos sabían lo que alguien era, las cosas que podía poseer, las relaciones que podía mantener o no tener, entre otras. Por el testimonio de don Joseph se puede pensar que existía una espacio-temporalidad de lo privado. El mundo del secreto y de los negocios privados ${ }^{23}$ se oponía al del

22 Al respecto se puede ver la reflexión, basada en información documental de Saben. Existen algunos trabajos para el territorio neogranadino, véase Colmenares, Ceballos (cap. 5) y Valencia.

23 Para defender el testimonio de su hermano, don Joseph aseveró frente a la sentencia del abogado: "Me parece también que es común sentir que el testigo inhábil y menos idóneo se admite en casos clandestinos que se suceden en secreto y tales en que por otros no se pueda saber", mientras don Ignacio apuntaba a señalar que aplique los 60 al principal que reconoce el referido don Egidio y debía de los réditos como anterior en tiempo al que reconoce el referido don Joseph Antonio y a que es obligado no sólo como fiador el citado don Egidio, sino privadamente por haber sido para sí el referido principal al que aplique los 20 pesos como título de que los 
rumor (aquello que circulaba en la pública voz y fama, en la notoriedad) y a la aceptación pública de los contratos; el secreto, de uno y otro y entre los otros que parecen ser uno y el mismo, permitía establecer ciertos espacios y sentimientos que no eran de todos si no de unos (tú-yo o él/nosotros), de él mismo dilatado en otro o de otro penetrado en él (yo o tú).

Una historia del secreto (de lo que no se decía, sino a uno o a unos cuantos) o de los negocios (de lo que no se hacía, sino con uno o con unos cuantos) estaría por hacerse. Por supuesto, no se puede olvidar que el secreto y los negocios, como lo público y notorio, dependían de las percepciones de una situación corporal donde la conciencia también estaba involucrada a lo mejor en forma de confianza o de complicidad. Estas, a su vez, aparecen como ciertos parámetros de comportamiento y valores que se esperan encontrar en el otro (Gráfico 1).

\section{Gráfico 1}

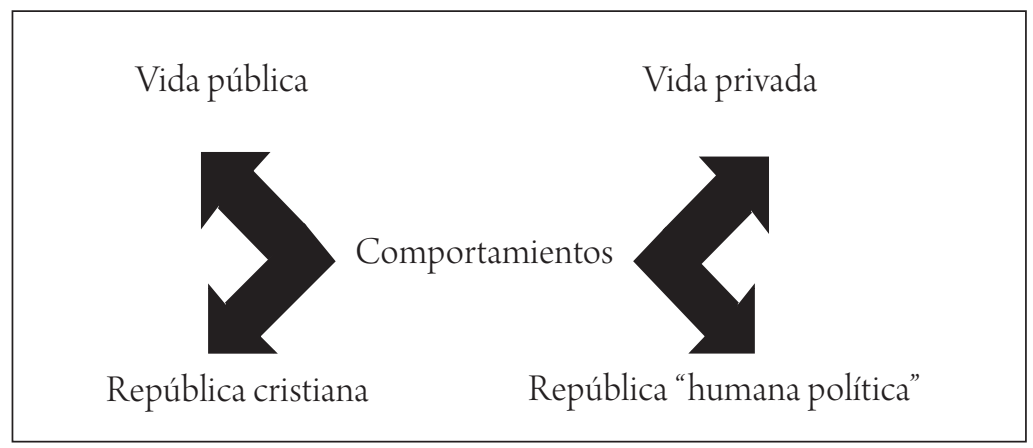

Incluso en el interior del orden familiar había ejes de carácter privado establecidos para beneficiar a algunos de sus miembros. La disputa pone en entre dicho el honor de los hermanos menores sin afirmar nada respecto al honor familiar precisamente porque como expresó más adelante don Joseph "es injuria notoria la que me hace el señor asesor de tratarme con vilipendio y desprecio [pues] soy hombre y casado aunque

debe el citado don Joseph Antonio y como quien en juicio debe ser primer demandado por la cantidad y en su virtud tengo ejecutado ("Causa", f. 193v.). 
con menos hijos que el señor asesor lo que me basta para estar fuera del dominio de mi hermano" (“Causa”, f. 231r.).

Esto debía hallarse directamente relacionado con el grave perjuicio de "nuestros intereses" - nótese que habla en plural, pero dando a entender al tiempo que los intereses "nuestros" (de los dos hermanos demandados) sí coincidían frente a los del demandante-. Por lo menos se debe tener en cuenta que detrás de tanta caridad, de ese mundo de paz, del sacrificio carnal entregado en los dolores de la pasión, la estilización del mundo extendido hacia la excelencia, lo puro, lo no erróneo, lo magnífico, ese mundo hacia el cual debían mirar los hombres para intentar alcanzarlo, aparecía otro de ciertas palabras que no se han estudiado todavía. A cada una de los términos, casi dicciones, que discurrían sobre el orden, la caridad, el amor, el perdón ${ }^{24}$, etc., se oponían otras que lamentablemente se han pasado por alto. Tal vez se sabe algo sobre la caridad, la justicia, la prudencia, pero poco sobre el egoísmo, la avaricia, el desprecio, el rencor, el engaño, la soberbia, la mala voluntad. Una infinidad de valores opuestos a las verdaderas virtudes de las que todos no disfrutaban, como bien acierta en recordarlo don Joseph al poner en duda el comportamiento privado de su hermano mayor.

El demandado continúo su defensa sobre un punto de verdadera importancia: el parricidio que, según el asesor, había deseado cometer y por el que debía pagar 10 pesos. Al respecto alegó, citando artículos de tratados de jurisprudencia, que "el que es provocado lo que hace es en justa defensa”, por lo cual no se le podía acusar de parricidio como pretendía hacerlo el doctor Tomas Arango. Todo lo contrario, lo que se debía interpretar con su expresión era que de: "no haber estado como estaba llevado de un natural sentimiento y encolerizado en un acto primo

24 Resulta excesiva la importancia que Bartolomé Clavero le otorga a estos valores en el momento de explicar por qué no "existía la economía", sino una antidora basada en los principios del catolicismo. Al parecer faltaría estudiar con precisión todas las pautas de comportamiento con las que actuaban los hombres del período colonial para no dar por hecho — como lo hace Clavero - lo afirmado en los textos de los savant y en los diccionarios de la época. Véase Clavero. Sobre el concepto de amor, véase, por ejemplo, Guerreau-Jalabert. 
le pude haber dado con un palo para reprimir su altanería acordándole que su padre fue un hombre tan pacífico y que su hijo no le representaba sino a los tigres de Hircana o leones de Libia” (“Causa”, f. 189r.). Pero va más lejos y deja en claro hasta dónde puede y debe llegar la justicia: "No sé seguro el efecto de mi voluntad (si es que la tuve) estando provocado de mi hermano de haberle injuriado y faltándole a respeto de algún modo sobre que no hay disposición alguna en derecho ni pena impuesta a los actos puramente internos".

La reflexión hace parte a lo leído en un libro del "señor Salgado", en el cual se exponía que la ley no castigaba "el efecto del ánimo sino el que siga el afecto de la voluntad". Así, la multa no debía ser cobrada "porque el hecho que toma como cierto fue puro imaginado y no estando en su libertad ni siendo su oficio tan despótico para imponer las penas sino las establecidas por las leyes" (“Causa”, f. 189r.).

Queda planteada la cuestión de cuáles son las pautas de comportamiento que se relacionan con cada una de las esferas de la sociedad colonial, de donde un sujeto determinado podrí escoger: proceder: Estas obedecen, a su vez, a dos parámetros: a cierto efecto del ánimo bajo el cual se actúa y a las decisiones tomadas "por el afecto de la voluntad". ¿Qué diferencia a cada una y de qué manera intervienen en los negocios? En la respuesta de don Ignacio se alude de nuevo a este problema y asocia la palabra con ciertos elementos "ánimo que manifiestan los deudores" y "siendo mi ánimo y procedimiento en este asunto tan limpio y arreglado" o refiriéndose a don Egidio, "cuyas acciones acreditan la maliciosa intención".

Sería necesario reconocer hasta dónde estas dos maneras de explicar el comportamiento están asociadas o disociadas de la conciencia y cómo pueden ser practicadas de diferentes formas, ya sea en la vida privada, pública o en la política o religiosa. Queda claro de todos modos que las instituciones son utilizadas por los agentes para favorecer sus intereses y que estos no pueden separar sus sentimientos en el momento de reclamar o de negociar. Así, por ejemplo, don Joseph no podía aceptar que su censatario no aceptara renovar la escritura respaldando la deuda con otros fiadores, 
pues según él la "contradice y resiste por la pasión enemiga que ha conciliado contra nosotros como del mismo hecho se deja ver", por lo que no se debía "patrocinar estas rencorosas demandas" ("Causa”, f. 197r.).

Al parecer la acusación de don Joseph sobre las pasiones de don Ignacio parece haber resuelto el problema, ya que en el auto siguiente este admitió renovar el crédito "para que se vea las falacias con que la contraria procede en suponer, procedo yo en este asunto con 'pasión'”. Sin embargo, ante la segunda asesoría, que resultó en una sentencia favorable a don Joseph, don Ignacio no pudo evitar presentar su desacuerdo. El conflicto "procesal" parece llegar a su fin en ese instante, pues por el mes de agosto de 1764 el escribano presentaba su escrito ante el señor gobernador para cobrar los gastos de escritura en que se había incurrido "estando cierto de que entre sí se hallan transados” (“Causa”, f. 201r.).

Sin lugar a dudas, se había llegado a un acuerdo. De nuevo se había arreglado un trato y, por lo tanto, se debía proceder a la escritura; en este caso, de nuevo, la firma de un contrato que no exhibiera las condiciones de su existencia y que permitiera hacer ver como si todo surgiera de lo afirmado en él. El pleito parece terminar donde parece empezar: en la firma de una escritura. El 11 de octubre de 1764, don Joseph Antonio y don Egidio de Navas, como principales deudores, junto con don Isidro de Navas y don Eusebio de Consuegra, como fiadores, se presentaron para firmar escritura de reconocimiento de 560 patacones "recibidos de mano" de don Ignacio de Navas, apoderado del Convento de Santa Clara.

Para respaldar la cantidad, don Joseph hipotecó una estancia de potrero que poseía en el sitio de Salazar, que por la parte de abajo lindaba con tierras del citado don Egidio, y por la otra, con las del doctor don Ignacio Cornejo, y en ella 60 cabezas de ganado, 8 mulas, un negro de 16 años y una esclava mulata con su hijo pequeño. Por su parte, don Egidio los impuso sobre una estancia de tierra "poco más o menos" en el sitio de Bucarica, de vivienda, platanares y cercas de piedra, que lindan por una parte con tierras de don Alejo de Navas, y por la otra, con tierras del citado Consuegra. ¿Aquí empieza o termina la historia? 


\section{Tratos y contratos: satisfacernos al ajustar cuentas}

La demanda que don Ignacio instauró contra don Joseph sólo puede ser entendida si se esbozan los elementos mencionados en los autos de la demanda que este siguió contra su otro hermano para cobrarle ciertas sumas que le debía. Lamentablemente los autos no están completos y por eso no aparece ni el inicio ni el final, todo empieza con la declaración jurada de las deudas de don Ignacio. Ellas permiten ver al tiempo su red de relaciones espaciales y crediticias (véase Cuadro 2).

Cuadro 2. Relación jurada que don

Egidio Navas debe por escritura o vales

* A don Isidro de Navas, 360 pesos a los que hipoteque $1 / 2$ estancia de mi vivienda en Río Frío, con 25 reses vacunas.

* Don Joseph Antonio de Navas, mi hermano, 750 patacones de su legítima paterna y materna como tenedor que he sido.

* Debo a don Lorenzo de Navas 870 patacones de 1/2 estancia de tierra en Río Negro entablada de cacao y obligada a dicha cantidad.

* A don Jaime Vargas, vecino del Valledupar, 364 pesos como consta por vale.

* Al Convento de señoras de Santa Clara de Pamplona con más otra cantidad que sacó en su nombre el sobre dicho don Joseph mi hermano, los cuales le aseguré yo en la abono del seguro que hizo él.

* A don Ignacio de Navas, mi hermano, 160 pesos, los que le aseguré con una estancia en el sitio de Bucarica.

* A dicho don Ignacio, mi hermano, 75 pesos.

* A don Joseph Prieto, 300 pesos, poco más o menos a los que le tengo hipotecada 1 estancia de tierra que le compre en Río Frío.

* A Francisco Acaxio, 50 pesos, de un pedazo de tierra que le compré el cual tengo hipotecado.

* Al señor alcalde don Antonio Salgar, lo que costare por su libro de cuenta, más 225 por vale. 


\section{Continuación}

* Joseph Durán, 125 patacones.

* Ignacio Fuensera de Santa Rosa, 88 pesos.

* Javier de Zarate de Vélez, 30 pesos.

* Juan Esteban Camacho de Vélez, 20 pesos.

* Bartolomé Mantilla, 100 pesos.

* Ignacio de Navas, hermano, 236 pesos 3 cuartillos de real, haciéndome constar por su apunte o cuenta formal.

* A la Cofradía de la Madre de la Concepción, 210 pesos.

* A Marcos de Rojas, 150 pesos.

* Bernardo de Esparza, 180 pesos.

* Al maestro don Javier Sánchez, 600 pesos, que están impuestos sobre la casa que tengo en la ciudad.

Para el seguro de los 400 pesos al convento tiene hipotecada $1 / 2$ estancia en Salazar y $1 / 2$ en que vivo en el sitio de Río Frío con un negro llamado Pascual y una mulata llamada Josefa, el ganado vacuno y las mulas que tengo y es declaración que el día de san Pedro de este próximo año pasado le entregué a mi hermano don Ignacio de Navas ochenta Patacones por mano de su yerno don Diego Mantilla y fuera por razón de los réditos de los cuatrocientos pesos que reconozco yo al Convento de santa Clara y otra tanta cantidad que reconoce el dicho hermano y no ha dado recibo. (17-1-1764)

Parece conveniente seguir de esta relación, por ejemplo, cuáles habían sido las cantidades que en moneda circularon y cuáles no. Se nota, en buena parte de los casos, que las sumas expresadas hacían parte de ajustes de cuentas. Para este caso sólo se requiere prestar atención a una sola de ellas. En su declaración, don Egidio expresó el deseo que tenía de resolver lo más pronto posible el problema:

... siendo todo mi deseo el de pagar como es justo al referido mi hermano y demás acreedores míos no lo he podido conseguir por la injuria de los tiempos que por lo irregular de ellos se pierden todas las cosechas del trabajo personal 
que como labrador aplico a mis haciendas de campo por lo que hago manifestación solemne de todos mis bienes. ("Civil”, f. 334r.)

La respuesta de su hermano fue inmediata:

... sobre la cantidad que a mí y a mi parte se nos debe digo que como consta de la relación jurada que presenta se halla confesada la cantidad que le tengo demandada y muchos más pesos que mi buena fe ignoraba y la arreglada conciencia de mi hermano tiene presente y manifestando en su narrativa que su deseo es pagar a sus acreedores por considerarme a mi atrasado y necesitado de lo que tan justamente me debe hace el tiempo que tengo significado suplico a Vuestra Excelencia se sirva de mandar que con la citación correspondiente se pase al embargo de sus bienes [... . Otro si digo que me haga la escritura de la estancia que me vendió en el sitio de Salazar. (“Civil”, f. 335r.)

Incluso entre los hermanos se conocía de "ciencia cierta" los intereses que correspondían a cada uno. No importaba si se debía dejar al otro "en la calle", incluso si era una persona con quien se estaba obligado por derechos naturales. Don Ignacio recomendó proceder al embargo de los bienes; esto significaba que tarde o temprano el patrimonio de su hermano (que por supuesto había conseguido con cruces personales, un pedazo de tierra que le compre ... y le tengo hipoteca ... las cosas dejadas por legítima paterna y materna) sería puesto en subasta pública; pero se anticipa y pide que don Egidio le haga la escritura de una estancia de tierra que le había vendido en el sitio de Salazar. Esta estancia parece ser un motivo importante en todo el problema entre los tres hermanos. No tanto la tierra, sino lo que pasó con ella al realizarse la negociación.

En su testimonio, don Egidio explicó los inconvenientes que tuvieron lugar en el proceso de venta de la referida estancia. Seis años después de que don Igancio le vendió a su hermano media estancia de tierra por un valor de 75 pesos, le preguntó "si la queria volver a tomar en lo mismo". Pero si aceptaba, debía comprarle también la mitad que don Igancio le había comprado a su otro hermano, don Miguel. El valor de esta segunda era de 75 pesos. Ante esta oferta "hallándonos yo y don Joseph Antonio mi hermano con más tierra en aquel paraje dentro el dicho don Joseph en comprarlo quien quedo en presencia del dicho mi hermano don Ignacio 
a pagársela por lo que en virtud de este trato como es público pasamos a cercar nuestra tierra". Sin embargo, como don Joseph se había retractado de dicho trato él estaba obligado a hacerle escritura y pagarle los 75 pesos (“Civil”, f. 338r.) ${ }^{25}$. Al reconstruir la situación de negociación, don Ignacio le respondió a su hermano que estaba claro no haberse adquirido derecho de propiedad alguno y que a pesar de eso:

... tergiversa el contrato con decir que mi hermano don Joseph Antonio fue el comprador de ella también expresa es él que debe el dinero según su relación jurada que uno y otro puede suceder pues como el citado don Egidio a mantenido este hermano como a pupilo no hay duda harían su traspaso o privado cambalache quedando yo hasta lo presente esperando el dinero o de una vez desengañado (como lo estoy hoy) que este era dificultoso adquirirlo y así paso a disponer de la tierra que de ninguna manera tiene el citado don Egidio en ella para manifestarla como sus bienes [... ] lo primero por no haber perfeccionado el contrato que sobre esta teníamos y lo segundo que corriendo esta por nuestro hermano Joseph Antonio no debe sin intervención de este pagar son sus fincas deudas que de él corresponden. ("Civil”, f. 339r.)

Aparecen en los testimonios dos maneras de percibir dicha operación. Mientras para el demandado se trataba solamente de un trato, para don Ignacio era un contrato a pesar de que no se había "perfeccionado" con la firma de la escritura. En una ocasión y en otra se trató de ajustes, de quedar a favor de alguien que esperaba, de un tiempo, espacio para hacer o dejar de hacer, para entablar actos en público o para alcanzar con mayor precisión lo deseado, para "engañar" a los que no tenían sentido del sentido, puesto en un juego disimulado, o sea, privado. El trato se oponía al protocolo (a lo enunciado en él, tratando de remitir a cláusulas legales), al servirle de situación de emergencia, al anticipársele. Se debería seguir explorando la manera como se llevaba a cabo esa praxis que no era otra cosa, sino las negociaciones mismas. Pero esos tratos también se deben validar de alguna manera. Debe existir algún rastro escrito donde se dejen dilucidar. 
Hasta el momento son las escrituras las que han llamado la atención de los historiadores. Se trata de hacerlas confesar sobre unas situaciones de las que difícilmente pueden dar luz. Muy rápido se puede notar que su descripción y ubicación precisa en una serie numérica deja por fuera las maneras y pautas de comportamiento a las que obedecen, aunque por supuesto permitan dar cuenta de otros fenómenos. Otro tipo de documentos tenían una importancia igual para las personas del período colonial, pues eran de uso cotidiano, más apegados a la labor de un estar constantemente renovando lo que se hace y se es. Los vales y otro tipo de documentos son importantes en este sentido. No porque simplemente afirmen ciertas cantidades que se deben; todo lo contrario, en este caso no se trata de sumas, sino más bien de satisfacción. Si en la escritura pública la satisfacción se alcanza por la entrega del dinero al renunciar a la non numerata pecunia, entonces ¿cómo se alcanzaba en los vales y otros documentos no legales?

En uno de los autos firmados por don Joseph, pero que aparecen en la demanda instaurada contra don Egidio (al parecer por equivocación del escribano), este declaró:

... estoy llano a pagarle a dicho mi hermano los setenta y cinco patacones de la media estancia de tierra que relaciona cada y cuando me otorgue la escritura de su venta siendo mi cargo el importe de ella y de la alcabala [... y por lo que en los citados autos hallado un escrito del referido mi hermano don Ignacio en el que expresa serle yo deudor de sesenta pesos y que a cuenta de ellos se me deberá rebajar el importe de una carga de tabaco y siendo mi deseo el de caminar con la mas perfecta armonía con dicho mi hermano don Ignacio y escoger escritos de demandas y respuestas sea de servir vuestra excelencia mande el referido presente el instrumento vale o cuenta por donde consta serle yo deudor de los referidos sesenta pesos y que prueba haber yo dado una carga de tabaco a cuenta de dicha deuda. ("Civil", f. 341)

Queda desvelado con esto un elemento importante. Según don Joseph, únicamente reconocería la deuda si su hermano presentaba el instrumento, vale o cuenta (y las tres eran cosas totalmente diferentes) "por donde consta serle yo deudor". No se ha analizado todavía el papel de estas hojas, papeles que permitían darle forma una y otra vez al juego. Faltaría analizar con mayor profundidad todas esas cuentas, seguirlas minuciosamente, 
contrastarlas, relacionarlas, intentar hacer ciertos tanteos posibles con ellas, asentarlas en un marco, evitar en lo posible descontextualizarlas, no acumularlas sumándolas para obtener grandes cifras; todo lo contrario, sería preferible particularizarlas, situarlas en medio de las relaciones personales en las cuales pudieron surgir. En este tipo de cuentas la satisfacción se alcanzaba solamente con el hecho de escribir sumas, con trazar columnas de inventarios de cosas junto a números.

Un agente se podía dar por satisfecho de cierta cantidad solamente con escribirla en un papel o, por el contrario, trazando ciertas sumas en medio de un cuaderno de cuentas se adquiría el compromiso con el otro. En fin: la escritura permitía crear el rastro de la satisfacción al crear la ilusión del reconocimiento de ciertas sumas. Estas, por supuesto, no tienen por qué ser dinero: son eso, sumas.

Los casos concluyen con las firmas de ciertas escrituras: una en la cual don Ignacio le vendía a don Joseph la $1 / 2$ estancia de tierra por 75 pesos (AHR, P 12, ff. 441v.-442r.); otra en la que don Egidio le vendía a su hermano menor una estancia más o menos por el precio de 600 pesos, que al parecer representaban la cantidad de su legítima paterna (AHR, $P$ 12, f. 480), y una tercera en la que don Egidio y don Joseph le "vendían" a don Juan Mantilla 1 1 1/2 estancias, gravadas en 560 pesos, a las madres monjas de Pamplona (AHR, P 12, ff. 494r-495v.). Esta última era venta y no traspaso, aunque lo único que haga el "comprador" era tomar en cargo la deuda. Esta vez tampoco el dinero debió haber circulado.

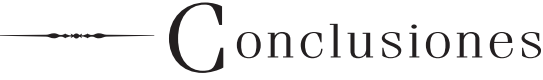

Más que respuestas, el análisis documental que se realizó en este artículo plantea algunas preguntas. Primero. La manera como surgen en un texto ciertos enunciados. No se puede tomar de manera inocente lo que se afirma en los documentos sin realizar un análisis sobre el espacio en el que surgen y sobre la manera como se encadenan sus conceptos. Ahora 
bien, queda claro que una cosa es un trato y otra muy diferente un contrato. Los últimos intentan esconder las operaciones realizadas por los agentes, otorgándoles ciertas cláusulas legales que no pertenecen a las estrategias de negociación, a la praxis en la cual se desatan sus relaciones. Es fundamental realizar análisis documentales que permitan reconocer estas maneras de actuar.

Segundo. Las pautas de comportamiento que intervienen en esas negociaciones. Con base en el texto analizado, se resaltó que aparecen varias esferas de organización del mundo a las cuales podían corresponder de manera particular valores, pautas aceptadas o rechazadas. Una cosa era la república cristiana, y otra, la política; una cosa era la vida privada, y otra, la pública. Esos valores no estaban solamente representados por los de tipo positivo (caridad, amor, piedad, etc.), sino también por otros como la envida, la mala voluntad (sobre todo), la pasión o la soberbia; pero lo más interesante es que los mismos agentes reconocen que existen ciertas combinaciones posibles: moverse entre la instancia de lo político y lo público, o de lo privado y lo religioso, etc.

Tercero. Las relaciones familiares sirven de espacio de consolidación de algunas de las negociaciones; sin embargo, se debe considerar que los agentes de esta sociedad saben distinguir bien entre las relaciones de amistad (compadrazgo, por ejemplo) y las de alianza (consanguinidad), y pueden optar por unas o por otras según los intereses que se hallen en juego.

Por último. Al separar los contratos de los tratos aparece un problema claro: ¿cómo se puede dar por satisfecho un agente al realizar un trato? En este sentido se resaltó lo importante que resultaban los vales y los cuadernos de cuentas, pues mediante su escritura alguien se podía dar por satisfecho sin que fuera necesario que circulara moneda en efectivo (cosa que, como se vio, parece necesario, por lo menos en términos de cláusula, en la firma de los contratos como escrituras). El proceso de escritura permitía dar lugar a las posiciones y transformaciones que tenían lugar en el sujeto mismo y en las relaciones en las que se encontraba situado según cada una de las instancias del mundo en las que intentaba moverse. 


\section{Bibliografía}

\section{FUENTES PRIMARIAS}

Archivo Histórico Regional, Bucaramanga, Colombia (AHR)

Archivo Girón, Causas Civiles Girón: 1763-1769

Archivo Girón, Protocolos Notariales (P) 12: 1761-1762; 1763-1769.

"Causa ejecutiva promovida por el apoderado del monasterio de Pamplona contra don Joseph Antonio y don Isidro de Navas por cantidad de pesos que se le adeudaban". Archivo Histórico Regional (AHR), Bucaramanga. Archivo Girón, Causas Civiles Girón 1763-1769, ff. 168r-244v.

"Civil entre partes. Don Ignacio y don Isidro de Navas por cantidad de pesos. Año de 1764". Archivo Histórico Regional (AHR), Bucaramanga. Causas Civiles Girón 1763-1769, ff. 330r-366v.

\section{FUENTES SECUNDARIAS}

Assadourian, Carlos Sempat. El sistema de la economía colonial: mercado interno, regiones y espacio económico. Lima: Instituto de Estudios Peruanos, 1982.

Bloch, Marc. Apología para la historia o el oficio del historiador. México: FCE, 2001.

Bourdieu, Pierre. "De la règle aux stratégies”. Choses dites. Paris: Minuit, 1987.75-93.

---. El sentido práctico. Madrid: Taurus, 1991.

---. Esquisse d'une théorie de la pratique (précédé de trois études d'éthnologie kabyle). Paris: Seuil, 2000.

---. Le bal des célibataires. Paris: Seuil, 2002.

Braudel, Fernand. La identidad de Francia. El espacio y la historia. T. 1. Barcelona : Gedisa, 1993.

Ceballos, Diana Luz. "Quyen tal haze que tal pague": sociedad y prácticas mágicas en el Nuevo Reino de Granada. Bogotá: Ministerio de Cultura, 2002.

De Certeau, Michel. La escritura de la historia. México: Universidad Iberoamericana, 1999.

Clavero, Bartolomé. La grâce du don: anthropologie catholique de l'économie moderne. Paris: Albin Michel, 1996.

Colmenares, Germán. "El manejo ideológico de la ley en un período de transición". Historia Crítica 4 (1990): 8-31.

---. Cali: terratenientes, mineros y comerciantes, siglo XVIII. Bogotá: Tercer Mundo, 1997. 
Daumas, Maurice. "Les conflits familiaux dans les milieux dominants au XVIII siècle". Annales 42.4 (1987): 901-23.

Duby, Georges. Economía rural y vida campesina en el occidente medieval. Barcelona: Península, 1991.

---. Los tres órdenes o lo imaginario del feudalismo. Madrid: Taurus, 1992.

Elías, Norbert. El proceso de la civilización: investigaciones sociogenéticas y psicogenéticas. México: Fondo de Cultura Económica, 1987.

Ferreira Esparza, Carmen Adriana. La economía espiritual: entre lo terrenal y lo celestial. Pamplona siglo XVIII. Bucaramanga: UIS-CER-SIC, 2001.

Ginzburg, Carlo. El queso y los gusanos: el cosmos según un molinero del siglo XVI. Barcelona: Muchnik, 1981.

Guerreau-Jalabert, Anita. “Caritas y Don en la sociedad medieval occidental”. Hispania. Revista Española de Historia 60.1 (2000): 27-62.

Guerrero, Amado. "Conflicto y poder político en la sociedad colonial. Girón siglo XVIII". En Cultura política, movimientos sociales y violencia en la historia de Colombia. VIII Congreso de Historia de Colombia, 1-40. Bucaramanga: UIS, 1993.

Ibarra, Antonio. "Mercado colonial, plata y moneda en el siglo XVIII: comentarios para un diálogo con Ruggiero Romano a propósito de su nuevo libro”. Historia Mexicana 2.49 (1999): 279-308.

Le Roy Ladurie, Emmanuel. Montaillou: aldea occitana de 1294 a 1324. Madrid: Taurus, 1988.

Romano, Ruggiero. Mecanismo y elementos del sistema económico colonial americano, siglos XVI-XVIII. México: El Colegio de México-Fideicomiso Historia de las Américas-FCE, 2004.

Saben, David. "La conscience et la peur: qui a tué le pasteur?". Actes de la Recherche en Sciences Sociales 51 (1984): 41-54.

Sarti, Raffaella. Vida en familia: casa, comida y vestido en la Europa moderna. Barcelona: Crítica, 2003.

Sopena. Diccionario latín-español. Barcelona: Sopena, 1985.

Soulodre-La France, Renée. Región e imperio: el Tolima Grande y las reformas borbónicas del siglo XVIII. Bogotá: ICANH, 2004.

Valencia Llano, Alonso. "El chisme y el escándalo en la sociedad colonial". Estudios Sociales 3 (1988): 33-48.

Fecha de recepción: $1^{\circ}$ de febrero de 2009.

Fecha de aprobación: 16 de marzo de 2009. 